\title{
ДИАГНОСТИКА И ЛЕЧЕНИЕ АНОМАЛЬНЫХ МАТОЧНЫХ КРОВОТЕЧЕНИЙ
}

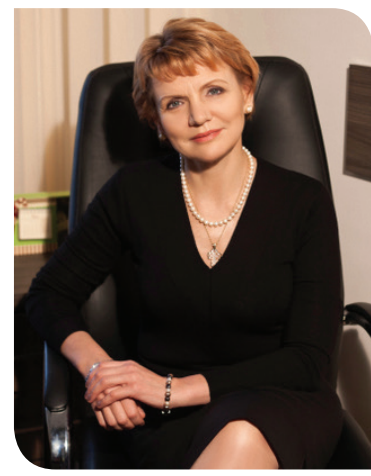

Т.Ф.ТАТАРЧУК

д. мед. Н., профессор, член-корр. НАМН Украины, заместитель директора по научной работе, заведующая отделением эндокринной гинекологии Института педиатрии, акушерства и гинекологии НАМН Украины

\section{H.В. КОСЕЙ}

д. мед. н., главный научный сотрудник отделения эндокринной гинекологии Института педиатрии, акушерства и гинекологии НАМН Украины

\section{Н.А. РЕДЬКО}

аспирант отделения эндокринной гинекологии Института педиатрии, акушерства и гинекологии НАМН Украины

\section{В.А. ДжУПИН}

аспирант отделения эндокринной гинекологии Института педиатрии, акушерства и гинекологии НАМН Украины

\section{ВВЕДЕНИЕ}

Проблема аномальных маточных кровотечений (АМК) занимает одно из лидирующих мест В современной гинекологической практике. Маточные кровотечения являются наиболее частым показанием к неотложной госпитализации. По данным Malmcolm G. Munro, 30\% женщин планеты страдают АМК. До 65\% пациенток репродуктивного возраста обращаются к специалистам по поводу чрезмерных менструальных кровотечений, 10\% всех гинекологических консультаций связаны именно с тяжелыми менструальными кровотечениями (Herve Fernandez, 2007) $[6,10,14,17]$.

Несмотря на достижения современной медицины, даже в развитых странах частота оперативных вмешательств при маточных кровотечениях остается высокой. Так, в США данная патология ежегодно является показанием для 300000 гистерэктомий. Нередко вследствие маточных кровотечений развивается железодефицитная анемия, что является крайне неблагоприятным фактором при наличии других соматических заболеваний. АМК создают предпосылки для физического, эмоционального, социального и материального дискомфорта пациентки $[1,11,14]$.

\section{ОБЗОР ЛИТЕРАТУРНЫХ ДАННЫХ И ПОСТАНОВКА ЗАДАЧИ ИССЛЕДОВАНИЯ}

Маточные кровотечения могут быть вызваны различными причинами: как маточными, так и внематочными, в том числе системными. На протяжении нескольких десятилетий в медицине использовался обобщающий термин «дисфункциональное маточное кровотечение» (ДМК), который не раскрывал сути проблемы. В различных странах, школах, учебных пособиях, клинических рекомендациях можно было найти различные определения ДМК, в связи с этим клиницисты разных стран по-разному понимали этот термин. Так, в некоторых странах (например, США) под этим термином подразумевалось любое аномальное кровотечение, которое расценивалось как симптом, в других же (в частности многих странах Европы) ДМК было диагнозом, включающим овуляторные и ановуляторные кровотечения при исключении анатомических причин. В связи с такими различиями и многообразием в определении термина «дисфункциональное маточное кровотечение» были связаны сложности в его использовании. Это, в свою очередь, приводило к некорректной интерпретации данных научных разработок, затрудняло взаимопонимание и обучение специалистов, усложняло проведение мультинациональных клинических исследований, международной статистики $[1,9,11,14]$.

Проблема несовершенства диагностики и терминологии была поднята в 2005 году, когда в Вашингтоне эксперты из 35 различных стран представили доклады о проблемах диагностики, лечения, а также терминологии маточных кровотечений. В результате обсуждения проблемы была выдвинута концепция необходимости пересмотра определения «дисфункциональные маточные кровотечения». Было рекомендовано отойти от терминов греческого и латинского происхождения и заменить их простыми четкими определениями, легко переводимыми на любой язык, понятными женщинам и мужчинам в различных обществах, врачам разных специальностей. Таким образом, был введен всеобъемлющий термин «аномальные маточные кровотечения» (АМК), подразумевающий любое маточное кровотечение, не отвечающее параметрам нормальной менструации женщины репродуктивного возраста $[9,14,16]$.

Согласно современным представлениям, группой экспертов определены параметры нормального менструального цикла: регулярность с отклонениями не более 2-3 дней в ту или иную сторону, длительность цикла 24-38 дней с продолжительностью менструального кровотечения 4-8 дней и кровопотерей не более 80 мл [19].

\section{Классификация маточных кровотечений}

Рабочая группа XIX Всемирного конгресса акушерства и гинекологии Международной федерации акушеров и гинекологов (FIGO), проходившего 4-9 октября 2009 года в г. Кейптаун (Южно-Африканская Республика), установила, что маточные кровотечения могут быть аномальными по всем вышеперечисленным показателям: регулярности, объему кровопотери, частоте или продолжительности кровотечения и подразделяются на:

3 острые - эпизод обильного кровотечения, требующего срочного врачебного вмешательства с целью предотвращения дальнейшей кровопотери. Острое АМК может возникать как внезапно, так и на фоне хронического АMK; s хронические - увеличение продолжительности менструального кровотечения, укорочение менструального цикла, повышение объема менструальной кровопотери более 80 мл в течение последних 6 месяцев, что, как 
правило, не требует экстренного врачебного вмешательства;

3 межменструальные - характеризуются обычно незначительными кровянистыми выделениями между четко предсказуемыми сроками менструации $[9,17,18]$.

Также на XIX Всемирном конгрессе акушерства и гинекологии (FIGO) Malcolm Munro предложил базовую классификацию АMK, которая была опубликована в книге Abnormal Uterine Bleeding (2010). Классификация была одобрена Исполнительным комитетом организации как «Классификационная система FIGO (PALM-COEIN) причин аномальных маточных кровотечений у небеременных женщин репродуктивного возраста» $[16,18]$.

Данная классификация включает 4 категории причин АМК, связанных со структурными изменениями в репродуктивных органах, объединенных аббревиатурой PALM, и 5 категорий, не связанных со структурной патологией, объединенных аббревиатурой COEIN (рис. 1).

Аббревиатура PALM составлена из заглавных букв структурных процессов в матке: Polyp (полип), Adenomyosis (аденомиоз), Leiomyoma (лейомиома), Malignancy (малигнизация) и hyperplasia (гиперплазия). Таким образом получилось в переводе с английского слово «ладонь».

Аналогично из заглавных букв нижеперечисленных нарушений сложилось название COEIN, в переводе с английского означающее «монета»: Coagulopathy (коагулопатия), Ovulatory dysfunction (овуляторная дисфункция), Endometrial (эндометриальная дисфункция), latrogenic (ятрогенная) и Not yet classified (еще не классифицированная).

Представленная классификация удобна в практической деятельности и получила широкое признание врачей. Однако важно понимать, что ее появление стало возможным благодаря развитию современных методов инструментальной и лабораторной диагностики.

Данная классификация нацеливает на определенный алгоритм диагностического поиска, что, в свою очередь, помогает правильно и грамотно подобрать лечение пациентке.

\section{Диагностика АMК}

Обследование женщин с АМК должно быть всесторонним и тщательным, в зависимости от клинической ситуации и доступных современных ресурсов.

Постановку диагноза «аномальное маточное кровотечение» необходимо начать с опроса пациентки. Важное значение имеют жалобы. При детализации которых необходимо остановиться на оценке объема кровопо-

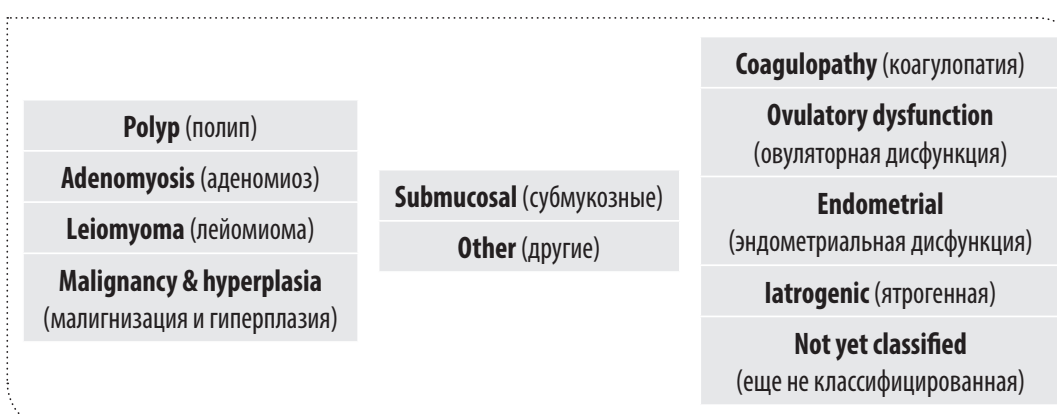

тери. Для объективной картины последнего можно использовать метод оценки количества санитарного материала с учетом степени его промокания. Для практического применения может быть использована методика РВАС (Pictorial Blood Assessment Chart), предложенная Higham и др. в 1990 г. [4]. В ходе менструации пациентка в данной таблице указывает количество тампонов или прокладок и степень их намокания кровью, что оценивается в баллах. Так, если тампон или прокладка окрашены слегка - 1 балл, если смочены наполовину - 5 баллов, полностью пропитанная прокладка или тампон - 20 баллов. Данное число баллов умножается на количество санитарного материала, использованного пациенткой за сутки. Наличие сгустков после удаления тампона или прокладки оценивается в дополнительные 5 баллов. В итоге суммируется количество баллов за весь период менструального кровотечения. Авторами методики указано, что избыточным маточным кровотечением, по их данным, являлся показатель более 100 баллов за период менструации (рис. 2).

\begin{tabular}{|c|c|c|c|c|c|c|c|c|c|}
\hline & \multicolumn{9}{|c|}{ ДАТА } \\
\hline БАлЛЫ & ПРОКЛАДКИ & ДЕНЬ 1 & ДEHЬ 2 & AEHb 3 & ДЕНЬ 4 & ДЕНЬ 5 & ДЕНЬ 6 & ДЕНЬ 7 & ДЕНЬ 8 \\
\hline 1 & w & & & & & & & & \\
\hline 5 & N & & & & & & & & \\
\hline \multirow[t]{2}{*}{20} & sin & & & & & & & & \\
\hline & \multicolumn{9}{|c|}{ ДАТА } \\
\hline БАлЛЫ & ТАМПОНЫ & ДЕНЬ 1 & ДЕНЬ 2 & ДEHb 3 & ДЕНЬ 4 & ДЕНЬ 5 & ДЕНЬ 6 & ДЕНЬ 7 & ДЕНЬ 8 \\
\hline 1 & r & & & & & & & & \\
\hline 5 & $\sim$ & & & & & & & & \\
\hline 20 & $\sim$ & & & & & & & & \\
\hline колич & ЗО БАЛЛОВ ЗА ДЕНЬ & & & & & & & & \\
\hline
\end{tabular}

При сборе анамнеза, в первую очередь, нужно уточнить наличие обильных менструаций с момента менархе, послеродовых кровотечений в анамнезе, кровотечений, связанных с хирургическими вмешательствами, повышенной кровоточивости из десен при стоматологических процедурах, появление синяков от ушибов, носовых кровотечений 1-2 раза в месяц, отягощенный семейный анамнез по нарушению гемостаза. Наличие вышеперечисленных признаков свидетельствует о ве-
РИСУНОК 2. ТАБЛИЦА ОЦЕНКИ ОБЪЕМА КРОВОПОТЕРИ ПО MЕТОДИКЕ PICTORIAL BLOOD ASSESSMENT CHART 
роятной патологии гемостаза и нацеливает на необходимость более углубленного обследования этой системы и консультации гематолога $[16,18,21]$.

Для исключения ятрогенных причин АМК необходимо уточнить наличие внутриматочных систем, прием оральных контрацептивов, использование других половых гормонов, антикоагулянтов.

С целью исключения беременности исследуют общий хорионический гонадотропин человека $\beta$. Параллельно с определением причины АМК как при острой, так и при хронической кровопотере для определения тактики лечения и наличия условий для проведения оперативного вмешательства следует выявить наличие анемии (концентрация гемоглобина и гематокрит, выполнить развернутый анализ крови, обязательно включающий количество тромбоцитов) (таблица 1).

\section{ТАБЛИЦА 1}

\begin{tabular}{|c|c|}
\hline $\begin{array}{l}\text { Лабораторное } \\
\text { обследование }\end{array}$ & Специальные лабораторные тесты \\
\hline Начальное обследование & $\begin{array}{l}\text { - Общий анализ крови } \\
\text { • Определение группы крови } \\
\text { • Тест на беременность }\end{array}$ \\
\hline $\begin{array}{c}\text { Начальная оценка нарушений } \\
\text { гемостаза }\end{array}$ & $\begin{array}{l}\text { - Частичное тромбопластиновое время } \\
\text { - Протромбиновое время } \\
\text { - Активированное частичное тромбопластиновое время } \\
\text { - Фибриноген }\end{array}$ \\
\hline $\begin{array}{c}\text { Начальная оценка болезни } \\
\text { Виллебранда }\end{array}$ & $\begin{array}{l}\text { - Антиген фактора Виллебранда* } \\
\text { - Кофактор ристоцетина } \\
\text { - Фактор VIII }\end{array}$ \\
\hline Другие тесты по показаниям & $\begin{array}{l}\text { - Уровень тиреотропного гормона } \\
\text { - Уровень железа в сыворотке } \\
\text { - Общая железосвязывающая способность сыворотки } \\
\text { - Уровень ферритина } \\
\text { - Печеночные функциональные тесты } \\
\text { - Chlamydia thrachomatis }\end{array}$ \\
\hline
\end{tabular}

ТАБЛИЦА 1.

ЛАБОРАТОРНОЕ ОБСЛЕДОВАНИЕ ПАЦИЕНТОК С ОСТРЫМ АМК (РЕКОМЕНДАЦИИ АМЕРИКАНСКОГО КОЛЛЕДЖА АКУШЕРОВ И ГИНЕКОЛОГОВ, 2013)

* подростки с обильными менструациями с менархе и взрослые женщины с аномальными тестами на нарушения гемостаза должны пройти обследование на наличие болезни

Виллебранда

** консультация гематолога может понадобиться для интерпретации показателей гемостаза
Далее проводится полное обследование пациентки, согласно критериям классификационной системы FIGO. С целью выявления структурной патологии (полипа эндометрия и/или полипа цервикального канала, аденомиоза, лейомиомы матки, в том числе субмукозной, гиперплазии эндометрия) проводят УЗИ органов малого таза, прежде всего с помощью трансвагинального трансдьюсера, в неясных случаях МРТ, соногидротубацию, диагностическую (офисную) гистероскопию.

Для выявления неструктурной патологии проводится скрининг на системное нарушение гемостаза при наличии вышеперечисленных факторов риска, оценка овуляторного статуса, оценка состояния эндометрия.

С целью определения овуляторного статуса проводится измерение уровня прогестерона в сыворотке или исследуется эндометрий в сере- дине лютеиновой фазы менструального цикла. В зависимости от наличия секреторной трансформации эндометрия, по данным гистологического исследования, мы можем судить о наличии или отсутствии овуляции в данном цикле, а также о недостаточности лютеиновой фазы.

Гистологическое исследование эндометрия при АMК показано у следующей категории женщин: старше 45 лет, младше 45 лет с гиперэстрогенными состояниями (ожирение, синдром поликистозных яичников и др.), у пациенток с рецидивирующими AMK [6, 8, 9, 15-17].

Используя современную классификацию, диагноз «АМК» состоит из вышеуказанных букв, к которым подставляется цифра 1 - в случае наличия патологии и 0 - при ее отсутствии (рис. 3) [18]. Современный диагноз «АМК» выглядит так, как представлено на рис. 3.
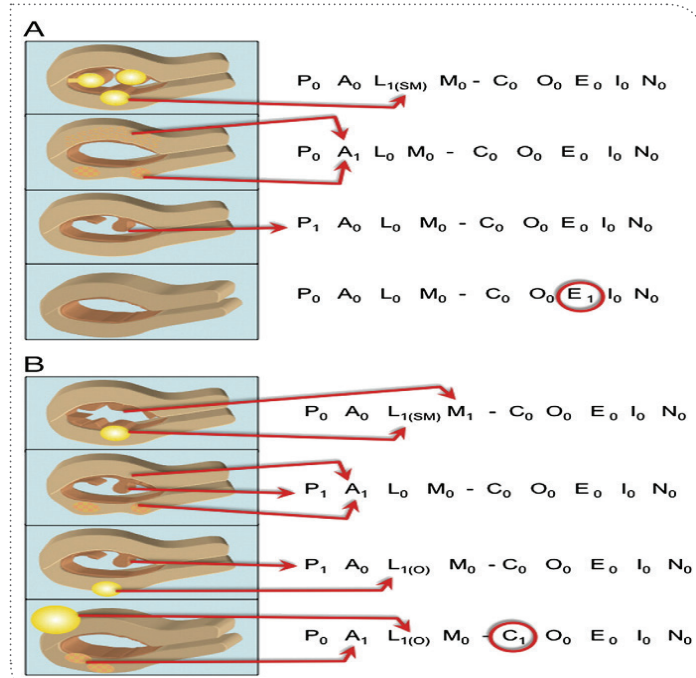

РИСУНОК 3.

АББРЕВИАТУРЫ РАLМ И СОЕIN ПРИ РАЗЛИЧНЫХ ПРИЧИНАХ АМК

На практике, если у пациентки, к примеру, выявлены нарушение овуляции и лейомиома (например, субмукозная) и не обнаружено никаких других нарушений, она может быть отнесена к следующей категории: AMK $\mathrm{P}_{0} \mathrm{~A}_{0} \mathrm{~L}_{1(\mathrm{SM})}$ $\mathrm{M}_{0}-\mathrm{C}_{0} \mathrm{O}_{1} \mathrm{E}_{0} \mathrm{I}_{0} \mathrm{~N}_{0}$. Поскольку в клинической практике такая категоризация АМК может быть слишком громоздкой, возможно сокращение, и характеристика этой пациентки может быть следующей: AMK-LSM.

При выявлении аденомиоза пациентке присваивается категория: AMK $\mathrm{P}_{0} \mathrm{~A}_{1} \mathrm{~L}_{0} \mathrm{M}_{0}-\mathrm{C}_{0}$ $\mathrm{O}_{0} \mathrm{E}_{0} \mathrm{I}_{0} \mathrm{~N}_{0}$, или AMK-A.

В случае выявления коагулопатии пациентка должна быть отнесена к категории: AMK-C . К этой категории должны быть отнесены также пациентки, получающие антикоагулянтную терапию.

Если у женщины выявлена ановуляция, она должна быть отнесена к категории: АMK-O, или сокращенно АМK-O. 
AMК, связанное с использованием экзогенных половых стероидов, внутриматочных спиралей, классифицируются, соответственно, как AMK-I, или сокращенно АМК-І.

\section{Патогенез}

На данный момент остается актуальным изучение механизмов маточного кровотечения. На XX Конгрессе Европейского общества по гинекологии, который состоялся в Брюсселе 17-21 сентября 2013 г., в своем докладе Malmcolm G. Munro акцентировал внимание на том, что до настоящего времени уделялось недостаточное внимание вопросам физиологии эндометрия, его паракринной и аутокринной регуляции, а также роли эндометриальных факторов в патогенезе физиологического и патологического маточного кровотечения. Фундаментальные исследования последних десятилетий дали возможность изучить локальные биохимические процессы в тканях, в том числе в эндометрии $[1,5]$.

Несмотря на прогресс в изучении вопросов физиологии эндометрия, патогенез идиопатического маточного кровотечения все еще до конца не изучен. Индукцию АМК связывают с изменениями в связях между сывороточными и клеточными концентрациями вазоактивных соединений, таких как простагландины, эндотелины, простациклины и фосфолипазы. Кроме этого, считается, что важную роль в менструальном гемостазе, а также в процессах отторжения и восстановления ткани эндометрия оказывают фибринолитические ферменты последнего. Имеются данные о повышении активности плазмина и активатора плазминогена в менструальной крови и эндометрии у женщин с АМК, вследствие чего усиливается фибринолиз. Это обусловливает один из основных механизмов патогенеза АМК $[5,11,14,18]$.

Для процесса нормального отторжения эндометрия (менструации) и своевременного прекращения кровотечения необходимо равновесие механизмов, способствующих возникновению кровотечения, и факторов, принимающих участие в его остановке.

Гемостаз - многоступенчатый каскадный процесс. При повреждении сосуда и возникновении кровотечения первой реакцией организма является выброс вазоконстрикторов, способствующих сужению просвета сосудов. Вслед за этим активизируется агрегация тромбоцитов, обеспечивая, совместно с вазоконстрикцией, временный первичный (тромбоцитарный) гемостаз. Впоследствии вступают в процесс сосудистая и тканевая тромбокиназы, инициирующие каскад взаимодействия факторов свертывания, в результате чего из протромбина образуется тромбин, под воздействием которого фибриноген превращается в фибрин, обеспечивающий окончательный (коагуляционный) гемостаз.

На этом этапе вступает в действие система фибринолиза важнейшего антитромботического механизма поддержания крови в жидком состоянии вне зоны кровотечения, в котором ключевую роль играет фибринолизин (плазмин), содержащийся в плазме в виде профермента (плазминогена). Активация плазминогена, подобно свертыванию крови, может осуществляться по внешнему и внутреннему механизмам. Активаторами внешнего механизма является тканевой эндотелиальный плазминогеновый активатор, а внутреннего комплекс фактора XIla (фактор Хагемана) с калликреином, антикоагулянтный комплекс протеинов C+S и др. (рис. 4).

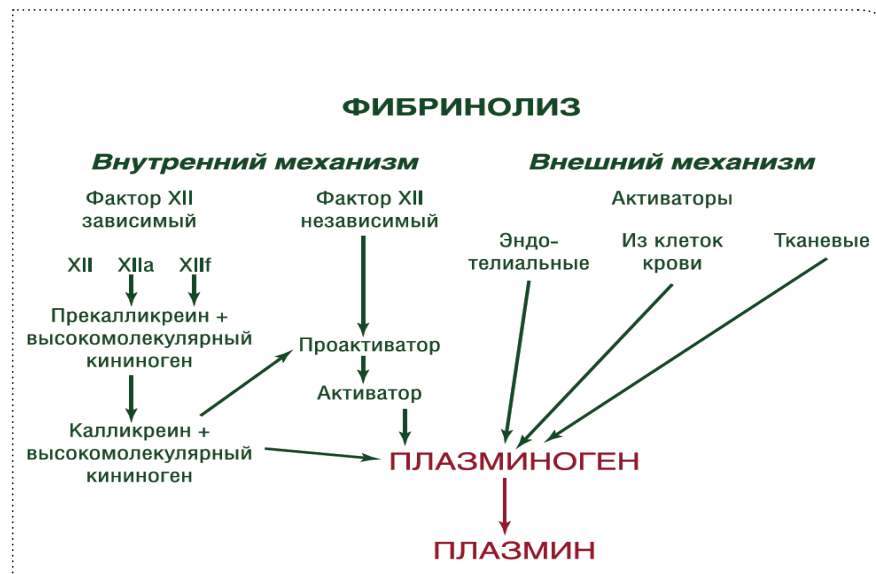

РИСУНОК 4. СХЕМА ПРОЦЕССА ФИБРИНОЛИЗА

Основной биологический смысл фибринолиза - обеспечение реканализации сосуда в случае образования тромба в его просвете.

Естественная система ингибиторов активатора плазминогена, антиплазмина и других протеаз направлена на поддержание равновесия между фибринообразованием и фибринолизом путем замедления и локализации процессов последнего. При избыточной активации плазмина может развиться патологическое состояние гиперфибринолиза, что может инициировать АМК и препятствовать его остановке.

В гемостазе в эндометрии фибринолиз имеет большую значимость, чем другие звенья гемостаза, в том числе активация тромбоцитов и прокоагуляционные процессы. Более того, выявлено, что в патогенезе АМК у женщин с лейомиомой матки активация фибринолиза также играет ключевую роль $[2,3,7,13,19]$.

До настоящего времени были раскрыты многие звенья в механизме возникновения кровотечения на фоне лейомиомы матки. Среди последних: интенсивное развитие венозной сети, развитие венозных сплетений в эндометрии, затрудненный отток крови от матки, снижение сопротивления в бассейне маточных артерий, механическая деформация полости и нарушение сократительной способности матки вследствие подслизистой локализации миоматозных узлов, увеличение площади эндометрия, локальная гиперэстрадиолемия, гипертензия в интрамуральных сосудах стенки матки, дисбаланс кальция и меди в миоматозном узле и в миометрии.

Достижения фундаментальных наук последних лет дали возможность расширить представления о механизме развития АМК у женщин с лейомиомой матки. Выявлено, что под воздействием тканевого фактора роста опухоли (TGF-ß3) в фиброматозных узлах снижается синтез ингибитора активатора плазминогена (PAI), в результате чего индуцируется работа активатора плазминогена (PA), который, соединяясь с плазминогеном, образует комплекс, обладающий фибринолитическим действием, инициируя АМК при лейомиоме матки, препятствуя образованию сгустков крови и способствуя продолжению кровотечения (рис. 5) $[5,14]$. 


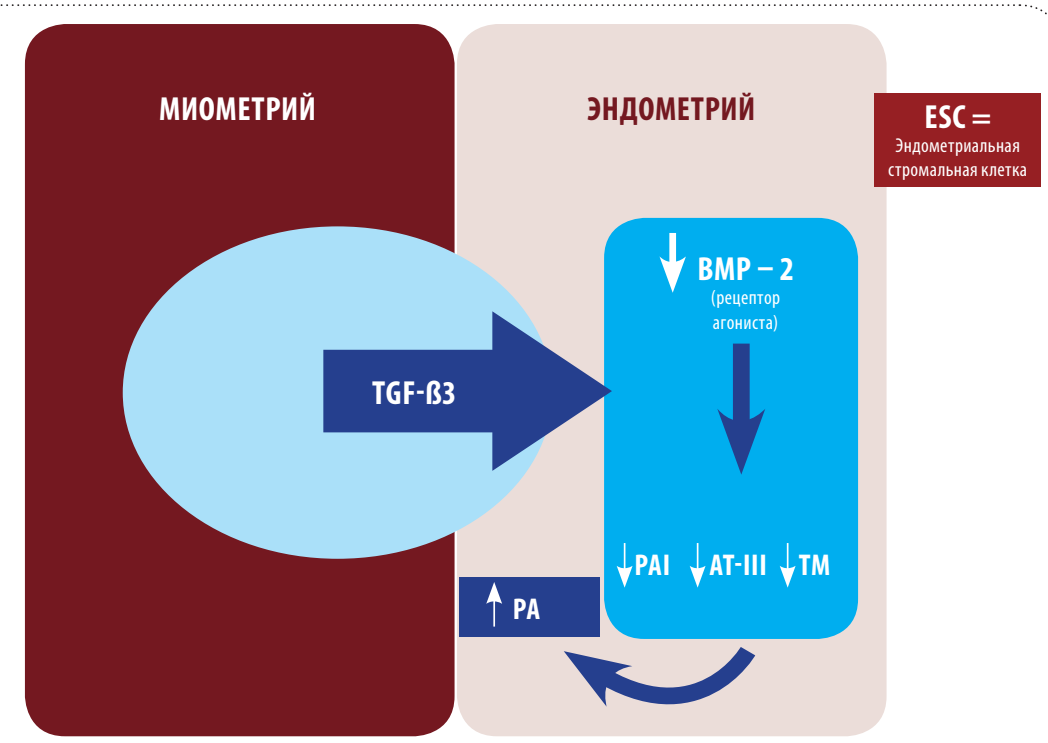
BMP - морфологический протеин
NGF - тканевой фактор
PA - активатор плазминогена
PAI - ингибитор ативатора плазминогена
ATIII - антитромбин III
ТМ - тромбомодулин

РИСУНОК 5.

ПОТЕНЦИАЛЬНЫЙ

МЕХАНИЗМ АМК ПРИ

ЛЕЙОМИОМЕ МАТКИ

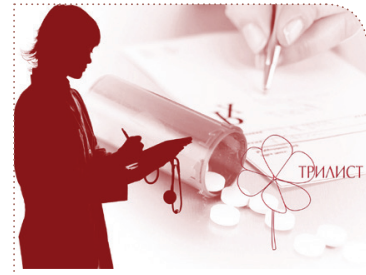

Эксперты ACOG считают, что после исключения структурной патологии эндометрия медикаментозная терапия является методом выбора, лечением первой линии АМК, особенно для идиопатического кровотечения
Повреждение эндометрия при АMК сопровождается избыточным поступлением в кровоток активаторов плазминогена из тканей и эндотелия поврежденных сосудов, что истощает систему естественных ингибиторов плазмина. Гормоны стресса (адреналин и норадреналин) активируют фактор Хагемана и запускают хагеман-зависимый механизм фибринолиза. Именно поэтому в современной гинекологии диагностику, профилактику и лечение гиперфибринолиза относят к важнейшим задачам интенсивной терапии кровопотери.

Маточные кровотечения на фоне отсутствия адекватного эритропоэза у больных миомой матки приводят к развитию железодефицитной анемии - клинико-гематологического симптомокомплекса, характеризующегося нарушением образования гемоглобина вследствие дефицита железа в сыворотке крови и костном мозге, развитием трофических нарушений в органах и тканях $[22,25]$.

Хроническая постгеморрагическая анемия у больных миомой матки способствует развитию органической тканевой гипоксии, на фоне которой повышается продукция коллагеновых волокон, создавая условия для интенсивного роста миоматозных узлов. Таким образом, замыкается порочный круг в патогенезе лейомиомы матки и маточных кровотечений $[24,27,28,29]$.

Обильная кровопотеря приводит к изменению содержания эритроцитов, падению концентрации гемоглобина, уменьшению объема циркулирующей крови. Вышеперечисленные изменения приводят к развитию гиповолемии [22, 27, 33], а также к нарушению реологических свойств крови, создавая фон для тромбоэмболических осложнений, в том числе тромбоэмболии легочной артерии [30].

На фоне гипоксии создаются благоприятные условия для размножения патогенной, особенно анаэробной, микрофлоры, что часто бывает причиной гнойно-септических осложнений после хирургических вмешательств [23, 25].

Таким образом, железодефицитная анемия у пациенток с миомой матки за счет вышеперечисленных патогенетических механизмов является тем фоном, при котором увеличивается частота осложнений во время операции и в послеоперационном периоде: возрастает объем интраоперационной кровопотери; увеличивается риск развития тромбоэмболических осложнений в послеоперационном периоде; снижаются репаративные способности тканей; повышается частота инфекционных осложнений в послеоперационном периоде.

\section{Лечение}

Лечение АМК может быть консервативным и хирургическим.

Группа экспертов ACOG сошлась во мнении о том, что после исключения структурной патологии эндометрия медикаментозная терапия является методом выбора, лечением первой линии, особенно для идиопатического АМК. Таким образом, можно избежать во многих случаях потенциальных осложнений, которые могут быть вызваны хирургическим вмешательством [6, 16-18].

С целью медикаментозной гемостатической терапии могут применяться препараты различных групп: вазоконстрикторы (такие как реместип, реже - вазопрессин), препараты, усиливающие агрегационные свойства тромбоцитов (этамзилат), средства, обладающие прокоагулянтным действием, стимулирующие образование факторов свертывания (викасол) или заместительная терапия при недостатке их образования, что имеет место при гемофилии (препарат новосэвен), плазма крови. Кроме этого, можно воздействовать на процесс фибринолиза, угнетая его активность и способствуя образованию прочного сгустка. Этот путь остановки кровотечения в эндометрии является наиболее безопасным, так как не влияет на систему гемостаза, не повышая тромбоопасность, а также - наиболее патогенетически обоснованным, учитывая ведущую роль активации фибринолиза в механизме развития АМК, в том числе и при наличии органической патологии, такой как лейомиома матки. Наиболее эффективным представителем данной группы препаратов является транексамовая кислота [12].

Установлено, что синтетические аминокислоты: ع-аминокапроновая и транексамовая обладают ингибирующим влиянием на фибринолиз. В основе механизма действия данных 
аминокислот лежит способность блокировать лизинсвязывающий участок в плазминогене, в результате чего плазминоген не может связаться с филаментом фибрина, а также не активируется посредством плазминогенного активатора, так как эта активация возможна только при условии соединения плазминогена и активатора плазминогена с фибрином (рис. 6) [3, 7, 12, 13, 19].

Кроме того, в результате угнетения образования кининов и других активных пептидов, принимающих участие в воспалительных реакциях АМК, транексамовая кислота оказывает определенный противовоспалительный эффект.

Гемостатический эффект транексамовой кислоты превышает таковой аминокапроновой кислоты в 10 раз, что обусловлено более стойкой и крепкой ее молекулярной структурой $[3,7,12,13]$.

Транексамовая кислота используется для лечения АМК в течение более четырех десятилетий во многих европейских странах. Впервые антифибринолитическая активность транексамовой кислоты была обнаружена японским исследователем Okamoto c соавторами в 1962 г. Позднее Melander и соавторы подтвердили наличие выраженной антифибринолитической активности и установили крайне низкую степень токсичности транексамовой кислоты, что стало основанием для широкого клинического применения последней. Впоследствии эффективность и безопасность транексамовой кислоты были доказаны в многочисленных клинических исследованиях $[12,19]$.

Учитывая данные о гемостазе в эндометрии, а именно - повышение концентрации ингибитора активности плазминогена при АMK, транексамовая кислота является наиболее патогенетически обоснованным и в то же время - самым безопасным средством лечения маточных кровотечений.

Поэтому на сегодня транексамовая кислота входит в первые линии терапии в большинстве современных руководств по лечению АМК: рекомендации Общества акушеров и гинекологов Канады (Society of Obstetricians and Gynaecologists of Canada, SOGC) за 2013 год, рекомендации Американского колледжа акушеров и гинекологов (American College of Obstetricians and Gynecologists, ACOG) за 2013 год, рекомендации Национального колледжа акушеров и гинекологов Франции (French National College of Obstetricians And Gynecologists, CNGOF) за 2008 год [6, 15, 16, 19].

Медикаментозное лечение также может включать следующие средства: эстрогены (в некоторых странах используются конъюгированные эквинные эстрогены) внутривенно,

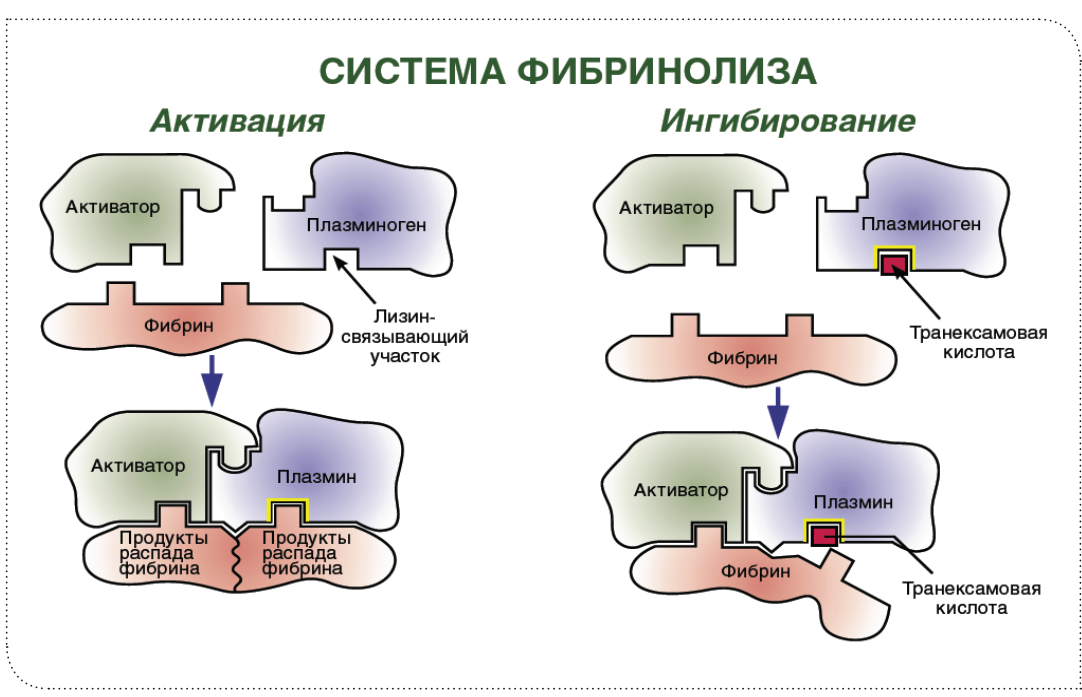

РИсунок 6.

МЕХАНИЗМ ДЕЙСТВИЯ ТРАНЕКСАМОВОЙ КИСЛОТЫ

комбинированные оральные контрацептивы (КОК), пероральные прогестины, нестероидные противовоспалительные средства (табл. 2 и 3).

Правильный выбор медикаментозного лечения зависит от индивидуальных терапевтических целей, необходимости, имеющихся заболеваний, переносимости терапии и побочных эффектов.

Учитывая многообразие нарушений и рисков, связанных с анемией, коррекцию данного состояния можно считать одним из основных этапов терапии AMK, а также непременным условием в процессе подготовки к хирургическим вмешательствам.

Лечение железодефицитной анемии условно можно разделить на следующие этапы: собственно купирование анемии; восстановление запасов железа в организме (терапия насыщения); поддерживающая (профилактическая) терапия [33].

Поэтому средство выбора для коррекции дефицита железа и уровня гемоглобина у больных железодефицитной анемией - лекарственные препараты, содержащие железо [25, 27, 28, 31, 32].

Все препараты железа разделяют на две основные группы:

1. Ионные железосодержащие препараты (солевые, полисахаридные соединения двухвалентного железа).

2. Неионные соединения, к которым относятся препараты трехвалентного железа, представленные железопротеиновым и гидроксид полимальтозным комплексами.

Ионные препараты железа представляют собой простые соли, содержащие двухвалентное железо (ионное, нестабильное), которое после поступления в кровь превращается в трехвалентное, связывается с трансферрином и используется для построения молекулы гемоглобина. Процесс преобразования двухвалентного железа в трехвалентное, благодаря потере одного электрона, может сопровождаться образованием свободных радикалов, способных повреждать стенку сосудов, оказывать негативное влияние на физиологические процессы в различных органах и тканях, а именно: вызывать перекисное окисление липидов, нарушать структуру мембранных и клеточных белков, повреждать клеточную ДНК и РНК, что обозначается как оксидативный стресс. С этим связывают побочные проявления, наблюдающиеся при ферротерапии солями двухвалентного железа (гастроинтестинальные расстройства: боль, тошнота, рвота, диарея, окрашивание зубов). Причиной повреждающего действия является также способность солей двухвалентного железа диссоциировать в водных растворах на двух- и трехвалентные ионы, которые, взаимодействуя с различными молекулами, образуют растворимые и нерастворимые соединения. 


\begin{tabular}{|c|c|}
\hline Негормональные препараты & $\begin{array}{l}\text { • Нестероидные противовоспалительные средства } \\
\text { • Антифибринолитики }\end{array}$ \\
\hline Гормональные средства & $\begin{array}{l}\text { • КОК } \\
\text { • Левоноргестрел-высвобождающая внутриматочная система } \\
\text { • Прогестагены в пролонгированном режиме (с5 по } 26 \text { день цикла) } \\
\text { • Депо медроксипрогестерона ацетата } \\
\text { • Даназол } \\
\text { • Агонисты гонадотропных рилизинг-гормонов }\end{array}$ \\
\hline
\end{tabular}

ТАБЛИЦА З. МЕДИКАМЕНТОЗНЫЕ МЕТОДЫ ЛЕЧЕНИЯ ОСТРЫХ АМК (РЕКОМЕНДАЦИИ АСОG, 2013) [16]

\begin{tabular}{|c|c|c|c|}
\hline Препарат & $\begin{array}{c}\text { Доза } \\
\text { и путь } \\
\text { введения }\end{array}$ & Режим & $\begin{array}{c}\text { Меры предосторожности } \\
\text { (согласно Управлению по контролю за пищевыми } \\
\text { продуктами и лекарственными средствами (ША, FDA) }\end{array}$ \\
\hline $\begin{array}{l}\text { Конъюгированные } \\
\text { эКвинныеэстрогены }\end{array}$ & 25 мг в/венно & Каждые 4-6 часов в течение 24 часов & $\begin{array}{c}\text { Те же, что и при назначении заместитель- } \\
\text { ной гормональной терапии }\end{array}$ \\
\hline $\mathrm{KOK}^{*}$ & $\begin{array}{c}\text { Монофазные } \\
\text { (30-50 мкг этинилэстрадиола) }\end{array}$ & $\begin{array}{c}\text { 3-4 таблетки в день в течение 3-7 дней, далее } 2 \text { таблетки в день в } \\
\text { течение } 2 \text { дней с переходом на } 1 \text { таблетку до 21-го дня приема }\end{array}$ & $\begin{array}{l}\text { Курение, возраст старше } 35 \text { лет и другие } \\
\text { факторы риска венозной тромбоэмболии }\end{array}$ \\
\hline $\begin{array}{l}\text { Медроксипрогестерон } \\
\text { ацетата }^{* *}\end{array}$ & 20 мг перорально & 3 раза в день в течение 7 дней & Те же, что и для назначения прогестагенов \\
\hline $\begin{array}{l}\text { Транексамовая кисло- } \\
\text { та }^{* * *}\end{array}$ & $\begin{array}{c}1,3 \text { г per os } \\
\text { или } 10 \text { мг/кг в/в (максимальная } \\
\text { доза } 600 \text { мг) }\end{array}$ & $\begin{array}{l}3 \text { раза в день в течение } 5 \text { дней } \\
\text { каждые } 8 \text { часов }\end{array}$ & $\begin{array}{c}\text { Нарушение цветных полей зрения, риски } \\
\text { венозной тромбоэмболии. } \\
\text { При приеме вместе с КОК - тщательное } \\
\text { наблюдение }\end{array}$ \\
\hline
\end{tabular}

* возможны другие режимы приема

** другие прогестины, дозы и режимы также могут быть эффективными

*** другие дозы и режимы могут быть эффективны

Основное отличие железополимальтозного комплекса состоит в том, что в его состав входит трехвалентное желе30 (неионное, стабильное), непосредственно использующееся для построения молекулы гемоглобина, вследствие чего препараты лишены возможного прооксидантного действия, обладают меньшим количеством побочных эффектов и лучшей переносимостью.

Существенно различаются механизмы всасывания этих двух групп препаратов. Так, всасывание железа из препаратов солей железа происходит главным образом в виде пассивной диффузии, согласно градиенту концентрации, и в меньшей степени - активно, что может привести к повышению концентрации свободного железа в сыворотке крови выше нормы, а в повышенной концентрации последнее может проявлять токсическое влияние [26-29].

С другой стороны, всасывание железа из препаратов простых солей железа может уменьшаться под влиянием содержащихся в некоторых пищевых продуктах веществ фитинов (рис, соя), фосфатов (рыба, морепродукты), танина (чай, кофе). Многие больные склонны запивать лекарства чаем, что в случаях приема препаратов солей железа может привести к образованию плохо растворимых комплексов с низкой их абсорбцией в кишечнике. Кроме того, всасывание железа и поступление его в организм из препаратов солей железа ухудшается при одновременном приеме ряда медикаментов (тетрациклины, антациды, соли кальция и магния). С учетом этого следует рекомендовать прием препаратов солей железа в различное время с другими вышеуказанными средствами.

Отличие абсорбции железа из препаратов железа гидроксид полимальтозного комплекса (ЖГПК) состоит в том, что она является активным процессом в виде кон- курентного обмена лигандами. В связи с этим уровень железа в сыворотке, объем распределения, константы элиминации после абсорбции в этих двух случаях существенно отличаются. Железо из железосодержащих комплексов всасывается постепенно, концентрация его в сыворотке нарастает медленно, и элемент быстро поступает в запасы, что исключает перенасыщение сыворотки крови железом и, соответственно, передозировку данными препаратами. Пищевые продукты и медикаменты не оказывают влияния на всасываемость железа в виде трехвалентной его формы из неионных препаратов (рис. 7).

Учитывая вышеперечисленное, в настоящее время наметилась тенденция смены солевых препаратов двухвалентного железа на равные по эффективности, но менее токсичные препараты трехвалентного железа на основе гидроксид полимальтозного комплекса, относящиеся к группе неионных соединений.

Ярким представителем данной группы является препарат Мальтофер - гидроксид полимальтозат железа. Особенностью строения представителей этого комплекса является наличие ядра трехвалентной гидроокиси железа, состоящего из 260 атомов с высоким содержанием железа в ядре (около 27\%), окруженного полимальтозной оболочкой, вследствие чего молекула характеризуется высокой молекулярной массой. Таким образом, по строению и валентности соединение железа в Мальтофере схоже с молекулой ферритина - естественного депо железа в организме (рис. 8) [26, 28].

Препараты трехвалентного железа на основе гидроксид полимальтозного комплекса обладают преимуществами, во многом обусловленными их высокомолекулярной 


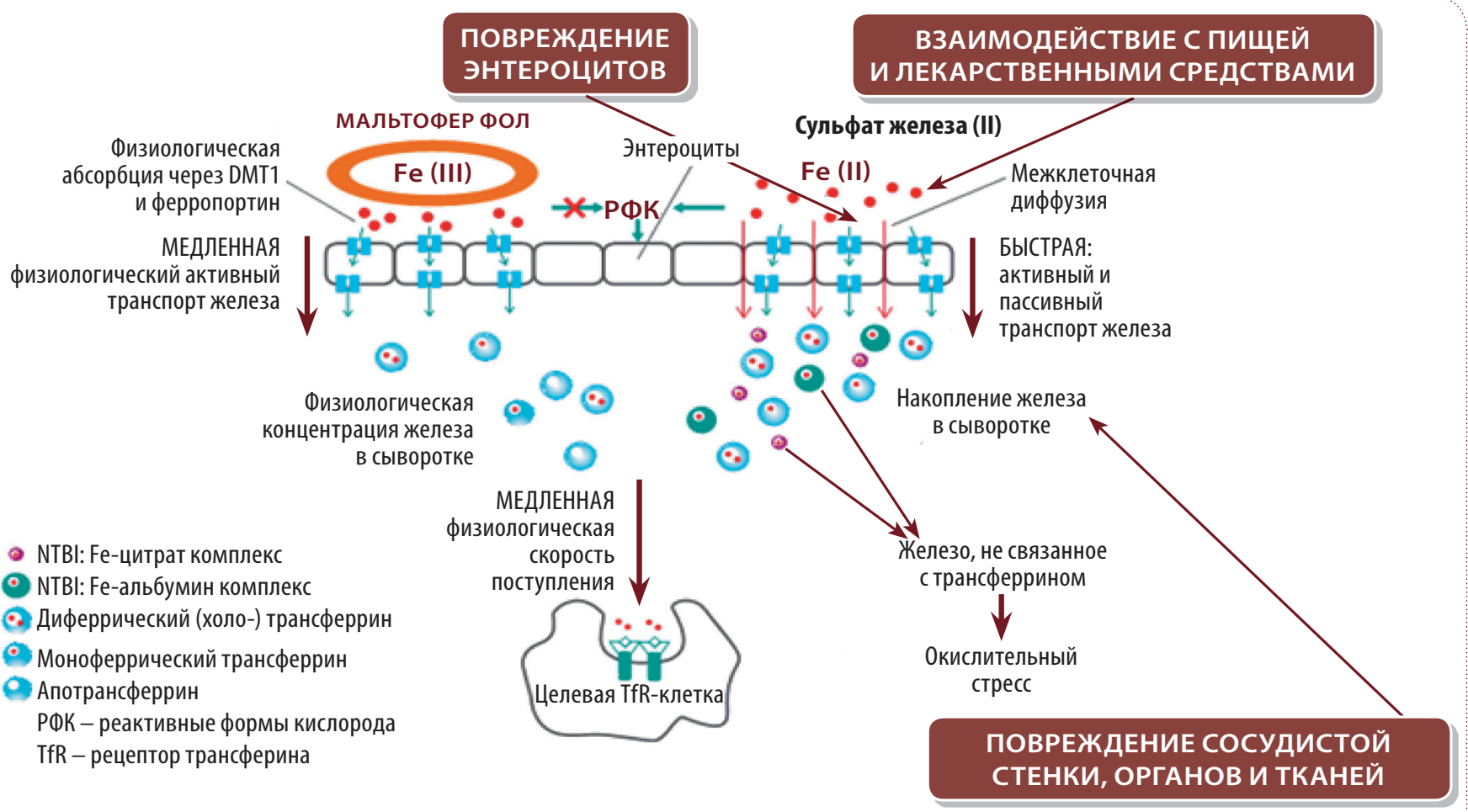

Предлагаемый механизм активного поступления железа из ЖГПК приводит к физиологическим концентрациям железа в сыворотке и крайне низким уровням железа, не связанного с трансферрином (ЖНТ). В отличие от этого, железо из солей железа (II) поступает путем как активного механизма, так и пассивной абсорбции, что приводит к повышению уровня ЖНТ в сыворотке. Общее количество утилизированного железа примерно одинаковое

РИСУНОК 7.

СРАВНИТЕЛЬНАЯ ХАРАКТЕРИСТИКА МЕХАНИЗМА ВСАСЫВАНИЯ ЖЕЛЕЗА ИЗ ГИДРОКСИД ПОЛИМАЛЬТОЗНОГО КОМПЛЕКСА И ПРЕПАРАТА СОЛИ ЖЕЛЕЗА

структурой (рис. 9): высокой эффективностью, безопасностью, отсутствием риска передозировки, интоксикации и отравления, отличной переносимостью, отсутствием потемнения эмали зубов и десен, приятным шоколадным вкусом, отсутствием взаимодействия с лекарственными препаратами и пищей, наличием антиоксидантных свойств [26].

Лечение препаратами железа должно быть длительным. После двух-, трехмесячного лечения и ликвидации гематологической картины железодефицитной анемии терапия не должна прекращается, а только уменьшается вдвое доза железосодержащего препарата, прием которого необходимо продолжить в течение 3 мес. К поздним критериям эффективности лечения железодефицитной анемии следует отнести нормализацию концентрации не только гемоглобина, но и сывороточного ферритина.

Учитывая вышеперечисленное, в клинической практике для экстренной терапии и противорецидивного лечения АМК мы широко используем препараты транексамовой кислоты, обладающие антифибринолитическим действием.

В нашей клинике была изучена сравнительная характеристика эффективности препарата Транексам у женщин с АМК на фоне лейомиомы матки, аденомиоза и у женщин с тяжелым продолжительным менструальным кровотечением (ТПМК) при условии отсутствия анатомической патологии.

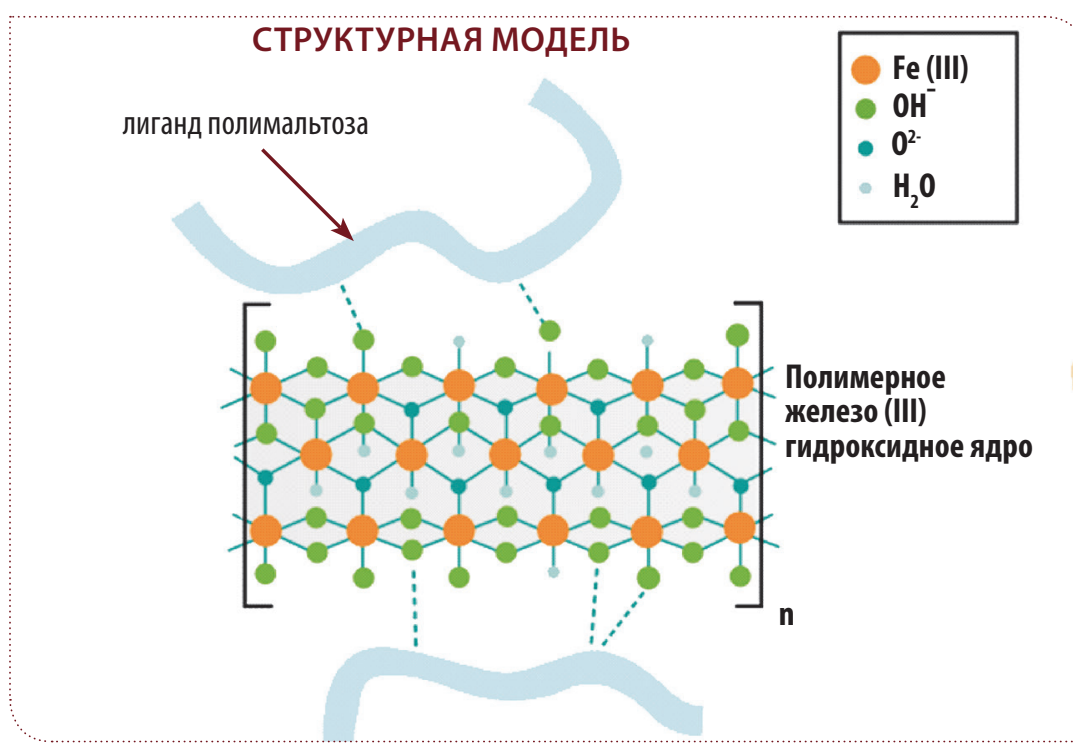

РИСУНОК 8 ХИМИЧЕСКАЯ СТРУКТУРА ПРЕПАРАТА МАЛЬТОФЕР

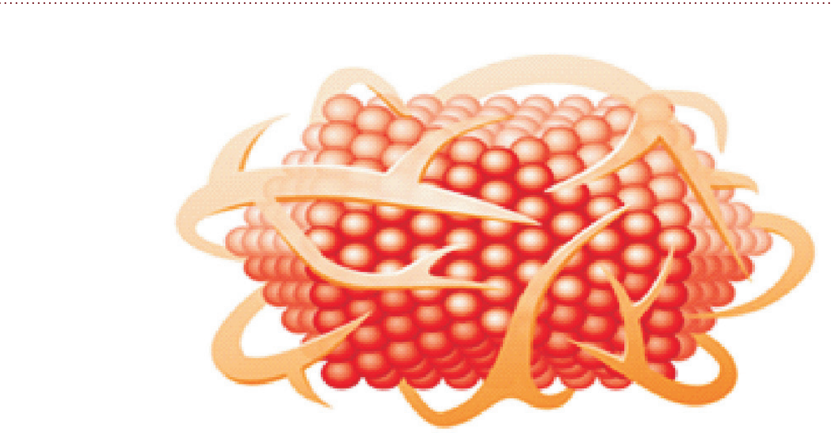

РИСУНОК 9.

ГРАФИЧЕСКАЯ СТРУКТУРА ГИДРОКСИД ПОЛИМАЛЬТОЗНОГО КОМПЛЕКСА 


\section{МАТЕРИАЛЫ И МЕТОДЫ ИССЛЕДОВАНИЯ}

Под нашим наблюдением находилось 60 женщин с АМК. Пациентки были разделены на 3 группы в зависимости от причины AMK: первую группу составили 20 женщин с ТПМК, вторую группу - 20 пациенток с АМК на фоне лейомиомы матки, третью группу - 20 женщин с АМК на фоне аденомиоза.

Все группы были сопоставимы по возрасту: средний возраст женщин I группы составил 48,2 \pm 1,2 года, II группы 46,3 \pm 1,7 лет, III группы - 46,1 \pm 1,3 года; по размеру узлов: средний диаметр узлов у пациенток II группы составил 6,8 $\pm 1,9$ см; объему менструальной кровопотери: средний объем кровопотери в I группе составил 234,7 $\pm 10,8$ балла по шкале Pictorial Blood Assessment Chart, во II группе - 241,3 \pm 20,1 балла, в III группе - 232,8 \pm 14,6 балла $\left(p_{1-2 ; 2-3 ; 1-3}>0,05\right) ;$ индексу массы тела - в I группе он составил 22,5 2 2,2; во II группе - $24 \pm$ 1,8; в III группе - 23,9 \pm 1,7.

Основной жалобой пациенток в 93,1\% случаев было увеличение обильности и длительности менструаций, что в $42,3 \%$ случаев сопровождалось симптомами хронической кровопотери: общей слабостью, повышенной утомляемостью, снижением работоспособности, изменением вкуса.

С целью вторичной профилактики развития АМК пациенткам был назначен Транексам по 500 мг 3 раза в сутки с первого по пятый день менструального цикла на протяжении трех месяцев.

Во всех группах проводилась терапия препаратами железа при уровне гемоглобина менее 110 г/л в ходе исследования.

Менструальная кровопотеря оценивалась по методике Pictorial Blood Assessment Chart. Подсчитывалось количество тампонов или прокладок и степень их намокания кровью, что оценивалось в баллах.

Мониторинг проводился через 1 и 3 месяца противорецидивной терапии.

\section{РЕЗУЛЬТАТЫ ИССЛЕДОВАНИЯ И ИХ ОБСУЖДЕНИЕ}

Объективное изучение показателей менструальной кровопотери выявило достоверную их стабилизацию уже после первого месяца лечения с дальнейшим уменьшением кровопотери после третьего месяца во всех исследуемых группах (рис. 10).

Объем менструальной кровопотери (по шкале Pictorial Blood Assessment Chart) также достоверно снизился с исходных 234,7 \pm 10,8 балла в группе с ТПМК до 177,2 \pm 14,3 балла в конце исследования ( $<0,05)$; с исходного 241,3 20,1 балла до $148 \pm 12,9$ балла в конце исследования ( $<$ 0,05) в группе с лейомиомой матки; соответственно с 232,8 \pm 14,6 балла до 155,4 \pm 13,7 балла в конце исследования ( $p<$ $0,05)$ в группе с аденомиозом. Следует отметить более выраженное уменьшение средних показателей менструальной кровопотери во II и III группах, то есть у пациенток с лейомиомой матки и аденомиозом. При этом по окончании третьего месяца лечения средние значения менструальной кровопотери во II (148 \pm 12,9 балла) и III группах (155,4 $\pm 13,7$ балла) были значительно ниже таковых в I группе (177,2 $\pm 14,3$ балла) $\left(p_{1-3 ; 2-3}<0,05\right)$.

Средняя длительность менструаций через 3 месяца терапии уменьшилась с 9,6 \pm 1,8 дня до 5,8 \pm 0,9 дня в І группе, с 10,2 \pm 1,5 дня до 6,2 \pm 0,6 дня во II группе и с 8,7 $\pm 1,6$ дня до 6,0 \pm 0,8 дня в III группе $\left(p_{1-3 ; 2-3}<0,05\right)$.

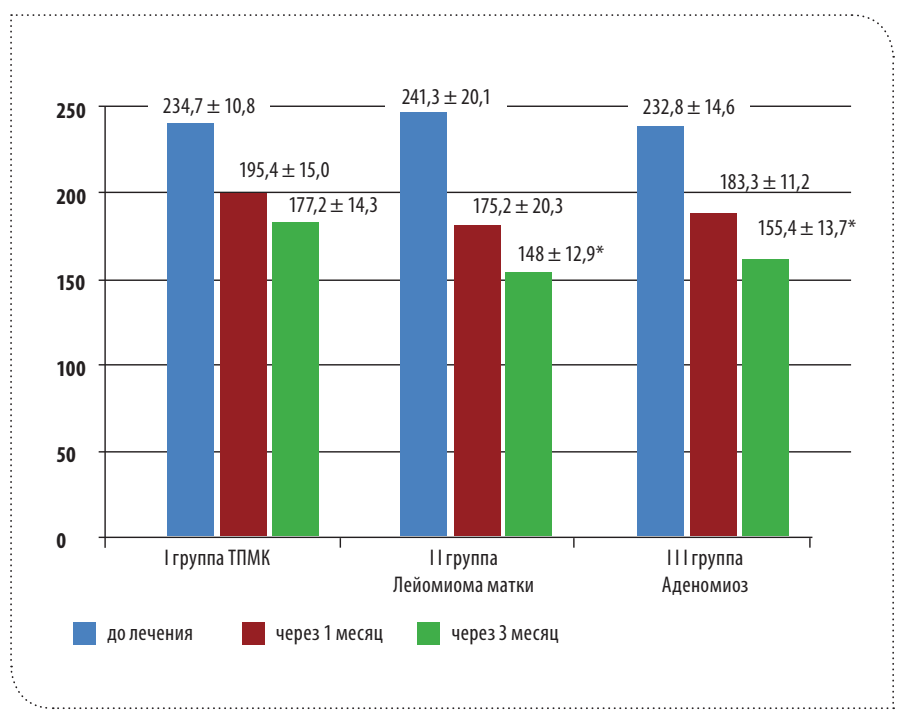

РИСУНОК 10.

СРЕДНЯЯ МЕНСТРУАЛЬНАЯ КРОВОПОТЕРЯ У ЖЕНЩИН С ТПМК

ЛЕЙОМИОМОЙ МАТКИ И АДЕНОМИОЗОМ ПРИ ЛЕЧЕНИИ ТРАНЕКСАМОВОЙ КИСЛОТОЙ, БАЛЛЫ

* разница достоверна относительно группы с ТПМК $(p<0,05)$

Отмечалась также положительная динамика показателей гемограммы: средняя концентрация гемоглобина в I группе увеличилась до 108,3 \pm 3,5 г/л через месяц после лечения и до $120,4 \pm 1,8$ г/л через 3 месяца после лечения по сравнению с 96,2 $\pm 3,1$ г/л до лечения; во II группе соответственно до 115,4 \pm 3,6 г/л через месяц после лечения и до $128,2 \pm 1,6$ г/л через 3 месяца после лечения по сравнению с 98,4 $\pm 3,4$ г/л до лечения; в III группе соответственно до 118,3 \pm 3,2 и 122,2 \pm 2,4 г/л против 99,8 \pm 2,9 г/л до лечения.

Следует отметить, что все пациентки отмечали хорошую переносимость препарата. Побочные эффекты не были зарегистрированы ни в одном случае клинического мониторинга в течение исследования.

\section{выводы}

Таким образом, во время проведенных нами исследований доказана эффективность препарата Транексам как в лечении, так и в профилактике АМК у пациенток с ТПМК, лейомиомой матки и аденомиозом. При этом гемостатический эффект Транексама наиболее выражено реализовался у пациенток с лейомиомой матки. Возможно, это связано с воздействием транексамовой кислоты на описанное ранее звено патогенеза в формировании AMК на фоне лейомиомы матки, при котором происходит активация фибринолиза за счет воздействия веществ, синтезирующихся в узлах миомы (рис. 4). Таким образом, назначение Транексама пациенткам с лейомиомой матки наиболее патогенетически обосновано.

Профилактическое применение антифибринолитических препаратов с первого дня менструального цикла у женщин с АМК обеспечивает уменьшение менструальной кровопотери и стабилизацию менструальной функции. Патогенетическая терапия АМК не только помогает избежать неоправданных хирургических вмешательств и рисков, связанных с ними, но и улучшает качество жизни пациенток, а также их психоэмоциональное состояние. При этом отмечается хорошая переносимость Транексама. Важным 
моментом описанной терапии является ее безопасность. В результате отсутствия влияния транексамовой кислоты на прокоагуляционные свойства крови не повышается риск возникновения тромбоэмболических осложнений, частота которых при АМК и анемии повышена, что выгодно отличает транексамовую кислоту от других гемостатических средств.

Вышеперечисленные факты свидетельствуют о высокой эффективности, хорошей переносимости, безопасности препарата Транексам, обладающего антифибринолитическим действием. Полученные данные дают повод отнести транексамовую кислоту к первой линии негормонального метода лечения AMК, в том числе при наличии лейомиомы матки и аденомиоза, которая может быть рекомендована даже как альтернатива хирургическим и другим методам лечения.

\section{ЛИTEPATYPA/REFERENCES}

1. Татарчук Т.Ф., Косей Н.В., Тутченко Т.Н.

Современная диагностика и лечение аномальных маточных кровотечений // Репродуктивная эндокринология. - 2012. - № 1. - С. 74-78.

Tatarchuk T.F., Kosei N.V., Tutchenko T.N.

"Current diagnosis and treatment of abnormal uterine bleeding.» Reproductive Endocrinology, № 1(2012):74-78.

2. Тимербаев В.Х., Валетова В.В.

Роль антифибринолитиков (Транексам) в современной экстренной медицине // Скорая медицинская помощь. - 2013. - № 2. - С. 51-61.

Timerbayev V.H., Valetova V.V.

"The role of antifibrinolytics (Tranexam) in modern emergency medicine.» Ambulance, 2(2013):51-61.

3. STADA. Транексам - новая технология кровесбережения в хирургии. C. $1-20$.

STADA. «Tranexam is a new technology saves of blood in surgery.», p. 1-20.

4. Рухляда Н.Н., Пахомов А.А., Брень А.К., Гасымова Д.М., Мельникова М.А. Опыт применения и сравнительная характеристика бусерелинадепо, гинестрила и транексама в снижении объема менструальной кровопотери у больных с аденомиозом // Проблемы репродукции. 2011. - № 5. - C. 50-53.

Rukhlyada N.N., Pakhomov A.A., Bren A.K., Gasymova D.M., Melnikova M.A. «Experience of use and comparative characteristics buserelin depot and Tranexam in reducing the volume of menstrual blood loss in patients with adenomyosis.» Problems of Reproduction, 5(2011):50-53.

5. Aamir T. Khan, Manjeet Shehmar, Janesh K. Gupta

"Uterine fibroids: current perspectives.», International Journal of Women's Health, 6(2014):95-114.

6. Abnormal Uterine Bleeding in Pre-Menopausal Women Journal of Obstetrics and Gynaecology Canada Volume 35, Number $5 \cdot$ volume 35, num?ro 5 May • mai 2013 1-32 http://sogc.org/wp-content/uploads/2013/07/gui292CPG1305E.pdf.

7. Alshryda S., Sarda P., Sukeik M., Nargol A., Blenkinsopp J., Mason J.M. "Tranexamic acid in total knee replacement: a systematic review and metaanalysis.» J Bone Joint Surg Br, 93(2011):1577-85.

8. Practice Bulletin No. 128

«Diagnosis of abnormal uterine bleeding in reproductiveaged women.» American College of Obstetricians and Gynecologists. Obstet Gynecol, 120(2012):197-206.

9. Fraser I.S., Critchley H.O., Broder M., Munro M.G.

«The FIGO recommendations on terminologies and definitions for normal and abnormal uterine bleeding.» Semin Reprod Med., 29(2011):383-90.

10. Fraser I.S., Langham S., Uhl-Hochgraeber K.

«Health-related quality of life and economic burden of abnormal uterine

bleeding.» Expert Rev Obstet Gynecol., 4(2) (2009):179-189.

11. Kadir R.A., Economides D.L., Sabin C.A., Owens D., Lee C.A.

«Frequency of inherited bleeding disorders in women with menorrhagia.» Lancet, 351(1998):485-9.
Также необходимо помнить, что коррекция анемии при лечении симптомной лейомиомы матки является важным этапом, существенно улучшающим качество жизни женщин с данной патологией, способствующим повышению эффективности органосохраняющих вмешательств, снижению риска возникновения осложнений.

При выборе препаратов для лечения железодефицитной анемии следует отдавать предпочтение неионным препаратам железа, в частности применению железа гидроксид полимальтозного комплекса как наиболее безопасного и высокоэффективного.

12. Lethaby A., Farquhar C., Cooke I.

«Antifibrinolytics for heavy menstrual bleeding.» Cochrane Database of Systematic Reviews 2000, Issue 4. Art. No.: CD000249. D0I: 10.1002/14651858. CD000249.

13. Lukes A.S., Moore K.A., Muse K.N., Gersten J.K., Hecht B.R., Edlund M. et al. «Tranexamic acid treatment for heavy menstrual bleeding: a randomized controlled trial.» Obstet Gynecol, 116(2010):865-75.

14. Malcolm $G$.

«Munro Abnormal Uterine Bleeding.» Cambridge University Press (2010):978-0521-72183-7.

15. Management of Abnormal Uterine Bleeding in Premenopausal Women Am Fam Physician. Jan 1;85(1) (2012):35-43.

16. Committee Opinion No. 557

«Management of acute abnormal uterine bleeding in nonpregnant reproductiveaged women.» American College of Obstetricians and Gynecologists. Obstet Gynecol, 121(2013):891-6.

17. Mary Gayle Sweet, Tarin A. Schmidt-Dalton, Patrice M. Weiss, Virginia Keith. «Madsen Evaluation and Management of Abnormal Uterine Bleeding in Premenopausal Women». American Family Physician, January 1, 2012 Volume 85, Number 1; 85(1):35-43.

18. Munro M.G., Critchley H.O., Broder M.S., Fraser I.S.

«FIGO classification system (PALM-COEIN) for causes of abnormal uterine bleeding in nongravid women of reproductive age.» FIGO Working Group on Menstrual Disorders. Int J Gynaecol Obstet, 113(2011):3-13.

19. Henri Leminen, Ritva Hurskainen

«Tranexamic acid for the treatment of heavy menstrual bleeding: efficacy and safety.» International Journal of Women's Health, 4(2012):413-421.

20. Stacy R. Ammerman, D.0.; Anita L. Nelson, M.D.

«A new progestogen-only medical therapy for outpatient management of acute, abnormal uterine bleeding: a pilot study». American Journal of Obstetrics \& Gynecology, june (2013): 499.e1-499.e5.

21. Von Willebrand desease in women American College of Obstetricians and Gynecologists Committee opinion № 580 Desember; 122(2013):1368-73.

22. Бурлев В.А., Коноводова Е.Н.

Современные возможности патогенетического лечения железодефицитной анемии у больных с миомой матки // Проблемы репродукции.-2003.-№ 5. C. 23-27.

Burlev V.A., Konovodova E.N.

«Modern possibilities of pathogenetic treatment of iron deficiency anemia in patients with Uterine myoma.» Reproduction Problems, 5(2003):23-27.

23. Давыдов А.И.

Восстановительное лечение после органосохраняющих операций у больных с подслизистой лейомиомой матки и аденомиозом // Вопросы гинекологии, акушерства и перинатологии. - 2011. - №6. - С. 13-21. 
Davydov A.I.

«Rehabilitation treatment after organ-serving surgery in patients with submucosal uterine leiomyoma and adenomyosis.» Gynecology, Obstetrics and Perinatology Issues, 6 (2011): 13-21.

24. Болевич С.Б., Меньшова Н.И.

Свободно радикальные процессы у больных железодефицитной анемией на фоне лечения препаратами железа // Терапевтический архив. - 2006. -

78(1). - C. 52-57.

Bolevich S.B., Menshova N.I.

«Free radical processes in patients with iron deficiency anemia during treatment with iron.» Therapeutic Archives, 78 (1) (2006):52-57.

25. Коноводова Е.Н., Докуева Р.С.-Э., Якунина Н.А.

Железодефицитные состояния вакушерско-гинекологической практике. РМЖ. - 2011. - 20. - С. 1228-1231.

Konovodova E.N., Dokuyeva RS.-E.,Yakunina N.A.

«Iron deficiency in obstetric practice.» RMJ, 20 (2011) 1228-1231. 26, 13, $27,21$.

26. Тихомиров А.Л., Сарсания С.И., Ночевкин Е.В.

Железодефицитные состояния в акушерстве и гинекологии. Грани проблемы. Современное лечение // Фарматека. http://www.rmj.ru/articles_7485.htm.

Tikhomirov A.L., Sarsaniya S.I., Nochevkin E.V.

«Iron deficiency in obstetrics and gynecology. Facets of the problem.»

Moderntreatment. Farmateka. http://www.rmj.ru/articles_7485.htm.

\section{7. Яглов В.В.}

Железодефицитные состояния у больных с маточными кровотечениями. Yaglov V.V.

«Iron deficiency in patients with uterine bleeding.»

28. Abnormal Uterine Bleeding and Uterine Fibroids: Medical Policy (Effective 10/01/2012) United Healthcare Policy Number: 2012T0442H.

29. Horne M.C.

«Consultative Hemostasis and Thrombosis.» Philadelphia, 15 (2002): 31-28.

30. Johnson-Wimbley T.D., Graham D.Y.

"Diagnosis and management of iron deficiency anemia in the 21st century.» Therap. Adv. Gastroenterol, 4 (3) (2011):177-84.

31. Iron deficiency anemia assessment, prevention and control. A guid for programme managers - Geneva: World Health Organization, 2001 (WHO/ NHD/01.3).

32. Nirmala Jaget Lakkawar, Santoshi Sankaran, Thirupurasundari Rangaswamy "Efficacy of Intravenous Administration of Iron Sucrose for Treatment of Iron Deficiency Anaemia in Patients With Abnormal Uterine Bleeding.»

Scientific Journal of the Faculty of Medicine in Niš, 29(2) (2012):59-68.

\section{ДІАГНОСТИКА І ЛІКУВАННЯ АНОМАЛЬНИХ МАТКОВИХ КРОВОТЕЧ}

Т.Ф. Татарчук, д. мед. н., професор, член-кор. НАМН України, заступник директора з наукової роботи, завідуюча відділенням ендокринної гінекології Інституту педіатрії, акушерства та гінекології НАМН України

Н.В. Косей, д. мед. н., головний науковий співробітник відділення ендокринної гінекології Інституту педіатрії, акушерства та гінекології НАМН України

Н.А. Редько, аспірант відділення ендокринної гінекології Інституту педіатрії, акушерства та гінекології НАМН України

В.А. Джупін, аспірант відділення ендокринної гінекології Інституту педіатрії, акушерства та гінекології НАмН України

Вивчена порівняльна характеристика ефективності препарату Транексам у жінок з аномальними матковими кровотечами (АмК) за відсутності анатомічної патології.

Удослідження увійшли 60 жінок з АМК, які були розділені на 3 групи: першу склали 20 жінок з важкою тривалою менструальною кровотечею, другу - 20 пацієнток з АМК на фоні лейоміоми матки, третю групу - 20 жінок з АМК на фоні аденоміозу.

3 метою вторинної профілактики розвитку АМК учасницям був призначений Транексам по 500 мг 3 рази на добу з першого по п'ятий день менструального циклу протягом трьох місяців. У всіх групах проводилась терапія препаратами заліза, якщо рівень гемоглобіну був менше, ніж 110 г/л в ході дослідження.

Моніторинг здійснювали через 1 і 3 місяці протирецидивної терапії.

У ході проведених досліджень було доведено ефективність препарату Транексам як у лікуванні, так і в профілактиці АМК у пацієнток 3 важкою тривалою менструальною кровотечею, лейоміомою матки та аденоміозом. При цьому гемостатический ефект Транексаму найбільш виражено реалізувався у пацієнток з лейоміомою матки. Побічні ефекти зареєстровані не були.

Ключові слова: аномальні маткові кровотечі, транексамова кислота, Транексам.

\section{DIAGNOSIS AND TREATMENT OF ABNORMAL UTERINE BLEEDING}

T.F. Tatarchuk, MD, professor, corresponding member of NAMS of Ukraine, Deputy Director for Research Work, Chief of the Endocrine Gynecology Department, SI «Institute of Pediatrics, Obstetrics and Gynecology, NAMS of Ukraine»

N.V. Cossey, MD, Chief researcher at the Department of Endocrine Gynecology, Institute of Pediatrics, Obstetrics and Gynecology, NAMS of Ukraine

N.A. Redko, a graduate student at the Department of Endocrine Gynecology, Institute of Pediatrics, Obstetrics and Gynecology, NAMS of Ukraine

V.A. Dzhupin, a graduate student at the Department of Endocrine Gynecology, Institute of Pediatrics, Obstetrics and Gynecology, NAMS of Ukraine

Comparative characteristic of the Tranexam efficacy in women with abnormal uterine bleedings (AUB) in the absence of anatomic pathology was studied.

The study included 60 women with AUB, which were divided into 3 groups: the first group consisted of 20 women with heavy menstrual bleeding, the second group - 20 patients with AUB on the background of uterine leiomyoma, the third group - 20 women with AUB on the background of adenomyosis.

Tranexam $500 \mathrm{mg} 3$ times a day from the first to the fifth day of the menstrual cycle for three months was appointed for secondary prevention of AUB. Iron therapy performed in all groups during the study if hemoglobin levels were less than $110 \mathrm{~g} / \mathrm{l}$.

At 1 and 3 months of preventive treatment monitoring was done.

During the studies it was proved the Tranexam effectiveness in the treatment as well as in the prevention of AUB in patients with heavy menstrual bleeding, uterine leiomyoma and adenomyosis. Hemostatic effect of the Tranexam is most pronounced realized in patients with uterine leiomyoma. Side effects were not registered.

Key words: abnormal uterine bleeding, tranexamic acid, Tranexam. 